\title{
Atık LDPE'nin asfaltın fiziksel ve ișlenebilirlik özelliklerine etkisi
}

\author{
Effect of waste LDPE on the physical and workability properties of asphalt
}

\author{
Tacettin GEÇKILL ${ }^{1, a}$, Ceren Beyza İNCE*2,b \\ İ́n̈nü Üniversitesi, Mühendislik Fakültesi, Inşaat Mühendisliği Bölümü, 44280, Malatya \\ ${ }^{2}$ İnönü Üniversitesi, Mühendislik Fakültesi, İnşaat Mühendisliği Bölümü, 44280, Malatya
}

• Geliş tarihi / Received: 01.05.2021 • • Düzeltilerek geliş tarihi / Received in revised form: 07.07.2021 Kabul tarihi / Accepted: 16.07.2021

\begin{abstract}
Öz
Bu çalışmada, bir atık plastik çeşidi olan LDPE'nin asfaltın fiziksel ve işlenebilirlik özelliklerine etkisi araştırılmıştır. Bunun için, asfalt ile LDPE arasında bir etkileşim sağlamak amacıyla B 70/100 saf asfaltına asfalt ağırlığının \% 2.5'i kadar Trietanolamin (TEOA) kimyasalı eklenmiştir. Elde edilen, asfalt-TEOA harmanına asfalt ağırlığının \% 1, 2, 3, 4 ve 5 oranlarında LDPE eklenerek modifiye asfaltlar elde edilmiştir. Saf ve modifiye asfaltların ilk olarak fiziksel özellikleri penetrasyon, yumuşama noktası, düktilite ve dönel ince film etüvü (RTFO) gibi geleneksel testlerle belirlenmiştir. Ayrıca, asfalt bağlayıcıların sıcaklığa karşı hassasiyetlerinin bir ölçüsü olarak kabul edilen penetrasyon indeksi (PI) değerleri de hesaplanmıştır. Daha sonra, bağlayıcıların işlenebilirlik özellikleri dönel viskozimetre (RV) deneyi ile, kimyasal karakterizasyonu ise taramalı elektron mikroskobu (SEM) ve X- ışını kııınımı (XRD) analizleri ile belirlenmiştir. Geleneksel test sonuçlarına göre; LDPE katkı oranının artışıyla modifiye bağlayıcıların sertliğinin arttığı ve sıcaklık hassasiyetlerinin azaldığı görülmüștür. RV deney sonuçlarına göre, LDPE katkı artışıyla bağlayıcıların karıştırma ve sıkıştırma sıcaklıklarının artış gösterdiği görülmüştür. SEM ve XRD analiz sonuçlarına göre, asfalt ile atık LDPE arasında kimyasal bir etkileşimin sağlandığı ve elde edilen asfalt-TEOA-LDPE karışımının homojen ve tek fazlı bir yapıda olduğu görülmüştür.
\end{abstract}

Anahtar kelimeler: Asfalt, Atık LDPE, Dönel viskozimetre, Karakterizasyon, Modifiye asfalt, SEM

\begin{abstract}
In this study, the effect of LDPE, a type of waste plastic, on the physical and workability properties of asphalt was investigated. For this, Triethanolamine (TEOA) chemical up to $2.5 \%$ by weight of asphalt was added to B 70/100 pure asphalt to provide an interaction between asphalt and LDPE. Modified asphalts were obtained by adding LDPE in the ratios of 1, 2, 3, 4 and $5 \%$ of the asphalt weight to the obtained asphalt-TEOA blend. The physical properties of pure and modified asphalts were first determined by conventional tests such as penetration, softening point, ductility and rolling thin film oven (RTFO). In addition, penetration index (PI) values, which are considered as a measure of the sensitivity of asphalt binders to temperature, were also calculated. Then, the workability properties of the binders were determined by rotational viscometer $(R V)$ test, and their chemical characterization was determined by scanning electron microscopy (SEM) and X-ray diffraction (XRD) analysis. According to traditional test result; It was observed that the hardness of the modified binders increased and their temperature sensitivity decreased with the increase of the LDPE additive ratio. According to the results of the RV test, it was observed that the mixing and compression temperatures of the binders increased with the increase of LDPE additive. According to the results of SEM and XRD analysis, it was observed that a chemical interaction between asphalt and waste LDPE was provided and the resulting asphalt-TEOA-LDPE mixture was homogeneous and single-phase.
\end{abstract}

Keywords: Asphalt, Waste LDPE, Rotational viscometer, Characterization, Modified asphalt, SEM

\footnotetext{
${ }^{* b}$ Ceren Beyza İNCE; c.beyzaince@gmail.com, Tel: (0507) 83155 91, orcid.org/0000-0002-6385-0964

${ }^{a}$ orcid.org/0000-0001-8070-6836
} 


\section{Giriş}

Dünya üzerinde artan nüfusla birlikte plastiklerin üretim ve tüketim hızının da giderek artış göstermesi atık malzemelerin birikmesine neden olmakta ve dolayısıyla büyük çevre kirliliği sorunlarıla birlikte ekolojik dengenin bozulmasına sebep olmaktadır. Özellikle gelişmekte olan ülkelerde çevre bilincinin yetersiz olması ve çevre koruma yasalarının da yetersiz oluşu sebebiyle bu bölgelerde yeryüzü hızla kirlenmekte ve büyük çevre sorunları meydana gelmektedir (Duranay ve Y1lgin, 2016).

Doğaya serbest birakılan plastikler fiziksel veya mekanik olarak kendi başına ayrışamaz ve parçalanamazlar. Atık plastiklerin doğada kalmasıyla zamanla plastik yığınları oluşur ve bu yığınlar da birçok haşerenin üremesine sebep olarak çeşitli hastalıkların oluşmasına neden olmaktadır. Bununla birlikte, bu atıklar yakılarak yok edilmeye çalışıldıklarında atmosfere vermiş oldukları zararlı gazlarla ekolojik dengenin tamamen bozulmasina sebep olmaktadır (Jung vd., 2018; Njeru vd., 2006). Tüm bu olumsuz durumlar, atık yönetimi konusunun önemini bir kez daha vurgulamaktadır. Atık yönetimi konusunda yapılan çalışmalar incelendiğinde çevre ve canlı sağlığının korunması açısından en etkili yöntemin geri dönüşüm olduğu, araştırmacılar tarafindan belirtilmiştir (Behl vd., 2014; Jung vd., 2018; Njeru vd., 2006).

Günümüzde en sık kullanılan plastik çeşitleri düşük yoğunluklu polietilen (LDPE), yüksek yoğunluklu polietilen (HDPE), polietilen tereftalat (PET), polivinil klorür (PVC), polipropilen (PP) ve polistiren (PS)'dir (Geçkil vd., 2020). Bu plastiklerin yaklaşık \%40'ını ise alışveriş sektöründe kullanılan taşıma poşetleri olarak bilinen kısa kullanım ömrüne sahip LDPE esaslı plastikler oluşturmaktadır (Almeida vd., 2020).

$\mathrm{Bu}$ çalışmada, atık plastik çeşitlerinden biri olan LDPE'nin karayolu mühendisliğinde bir katk1 malzemesi olarak kullanımı araştırılmıştır.

Yol mühendisliğinde bir kaplama çeşidi olan sıcak karışım asfalt (HMA) kaplamalar, belirli bir gradasyona sahip agreganın belirli orandaki asfalt ile uygun karıştırma koşullarında asfalt plentinde karıştırılmasıyla elde edilmektedir. HMA'da az miktarda bulunan asfalt bağlayıcılar, agrega daneleri ile birleştiğinde onları birbirine bağlayarak, düzgün bir kaplama yüzeyi oluşturarak ve iyi bir sürüş konforu sağlarlar (Geçkil ve Seloğlu, 2018).
Asfalt viskoelastik ve termoplastik bir malzeme olması sebebiyle sıcaklık, çevre ve çeşitli trafik yükleri altında HMA kaplamanın farklı davranışlar sergilemesine sebep olmaktadır. Bu durum, HMA kaplamada kalıcı deformasyon, yorulma çatlakları ve düşük sıcaklık çatlakları gibi bozulmalara neden olmaktadır (Airey, 2002; Geçkil ve Seloğlu, 2018). $\mathrm{Bu}$ bozulmaları en aza indirmek veya ortadan kaldırmak ve kaplamanın performansını geliştirmek amacıyla günümüzde çeşitli katkı malzemeleri kullanılarak asfaltlar modifiye edilmektedir (Tunç, 2007). Modifikasyon için başta polimer kökenli malzemeler olmak üzere çeşitli yağlar, filler malzemeler, kauçuk, elyaflar ve çeşitli çözücüler gibi katk1 malzemeleri kullanılmaktadır (Geçkil vd., 2020; Tunç, 2007). Ancak bu katk1 malzemelerinden birçoğunun ekonomik olmaması sebebiyle, araştırmacılar son zamanlarda asfalt modifikasyonunda atı malzemeleri kullanmaya başlamışlardır (Ahmedzade vd., 2014).

Bir atık plastik çeşidi ve polimer kökenli bir malzeme olan LDPE'nin asfalt modifikasyonunda kullanıldığı çalışmalarda, LDPE katkısıyla modifiye bağlayıcıların yumuşama noktasının ve viskozitesinin arttığı, penetrasyon ve düktilite değerlerinin ise azaldığ 1 görülmüştür. Ayrıca LDPE'nin asfaltın reolojik özelliklerinin iyileştirdiği de birçok çalışmada ifade edilmiştir (Al-Hadidy ve Tan, 2009; Nejres vd., 2020; Punith vd., 2007). LDPE'nin sicak karışımlarda kullanıldığı çalışmalarda ise, karışımların Marshall stabilite, esneklik modülü ve nem duyarlılı̆ğna karşı iyileşmeler meydana geldiği görülmüştür (AlHadidy ve Tan, 2009; Awwab ve Shbeeb, 2007; Nkanga vd., 2017).

Ancak, LDPE kullanılarak yapılan çalışmalarda LDPE'nin asfalt içerisinde sadece fiziksel olarak dağglım gösterdiği ve asfalt ile herhangi bir kimyasal etkileşim kurmadığ 1 görülmüştür. $\mathrm{Bu}$ sebeple LDPE katkısı asfalt modifikasyonunda genellikle farklı polimerle birlikte kullanılmıştır. Çünkü LDPE’nin özgül ağırlığının asfaltın özgül ağırlığından düşük olması sebebiyle karıştırma sonrasında LDPE yüzeyde kalarak karışımın farklı davranmasina sebep olmaktadır. Bu durum, LDPE katkılı bağlayıcıların yüksek sıcaklıktaki depolama stabilitesi üzerinde olumsuz bir etki yaratmaktadır. $\mathrm{Bu}$ yüzden araştırmacılar asfalt ile kimyasal reaksiyon oluşturabilen polimerler üretimine (reaktif terpolimerler gibi) veya polimer ile asfalt arasında kimyasal reaksiyon oluşturabilen çeşitli katkılar kullanmaya başlamışlardır (Ahmedzade vd., 2014; Jasso vd., 2015; Polacco vd., 2015). 
Bu çalışmada ise, atık LDPE katkısının asfaltın fiziksel ve işlenebilirlik özellikleri üzerindeki etkisi araştırılmıştır. Bu amaçla, asfalt ile LDPE arasında kimyasal bir etkileşim sağlamak ve homojen tek fazlı yapıda bir karışım elde etmek amacıyla TEOA kimyasalı kullanılmıştır. Çalışmada, atık LDPE modifiyeli asfaltların fiziksel özellikleri penetrasyon, yumuşama noktas1, düktilite ve RTFO gibi geleneksel testlerle, işlenebilirliği RV deneyiyle, karakterizasyonu ise SEM ve XRD analizleriyle belirlenmiştir.

\section{Materyal ve metot}

\subsection{Materyal}

Çalışmada, modifikasyon için penetrasyon sınıfı B 70/ 100 saf asfalt, atık LDPE ve asfalt ile LDPE arasında kimyasal reaksiyon sağlamak için TEOA kullanılmıştır. TEOA, amin grubu bir kimyasal olması sebebiyle bir yapıya kolaylıkla bağlanabilen organik bir baz türüdür. TEOA kullanımı ile asfalt ve LDPE arasında kimyasal bir bağ kurularak faz ayrışması sorunu ortadan kaldırılmaya çalışılmıştır. Kullanılan malzemeler Şekil 1'de, saf asfaltın geleneksel özellikleri ise Tablo 1'de verilmiştir.

Katkı olarak kullanılan atık LDPE, Bursa-SÖZAL Kimya LTD.ŞTİ.'den tedarik edilmiştir. LDPE'nin kimyasal özellikleri Tablo 2'de verilmiştir.

Asfalt ile LDPE arasında kimyasal bir etkileşim sağlamak amacıyla kullanılan TEOA'nın özellikleri Tablo 3'te verilmiştir.
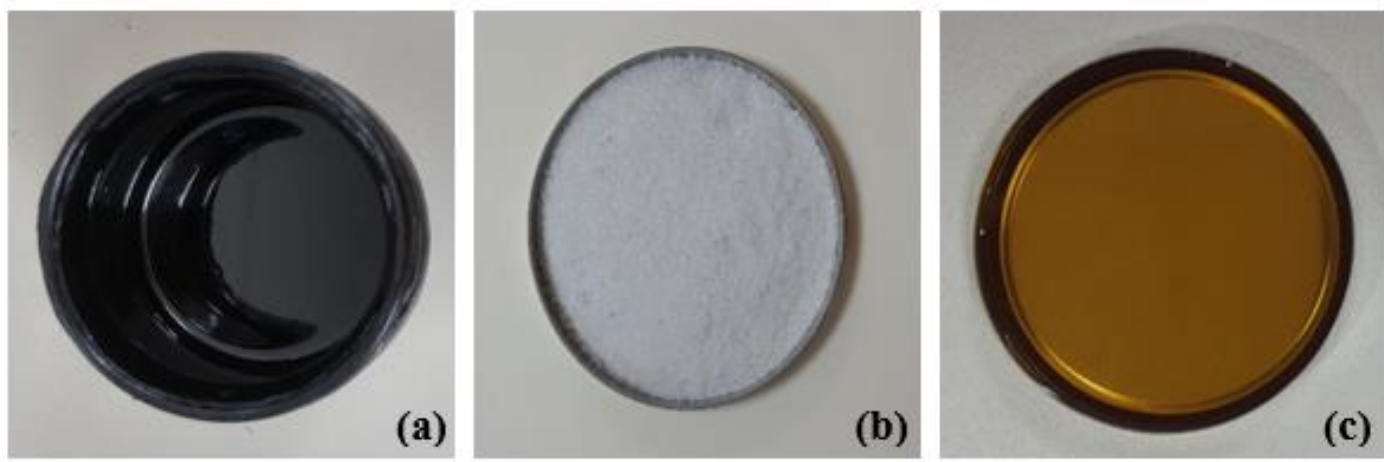

Şekil 1. Saf asfalt (a); atık LDPE (b); TEOA (c)

Tablo 1. Saf asfaltın özellikleri

\begin{tabular}{cccc}
\hline Özellik & Standart & Limit & Sonuç \\
\hline Penetrasyon $(0.1 \mathrm{~mm})$ & ASTM D5 & $70-100$ & 88 \\
Yumuşama noktas1 $\left({ }^{\circ} \mathrm{C}\right)$ & ASTM D36 & $43-51$ & 46.75 \\
Düktilite $(\mathrm{cm})$ & ASTM D113 & min. 100 & $>100$ \\
Parlama noktas1 $\left({ }^{\circ} \mathrm{C}\right)$ & ASTM D92 & min. 230 & 238 \\
Özgül ağırlık $\left(\mathrm{gr} / \mathrm{cm}^{3}\right)$ & ASTM D70 & $1.0-1.1$ & 1.038 \\
\hline
\end{tabular}

Tablo 2. LDPE'nin özellikleri (Beşergil, 2008; Sen vd., 2015)

\begin{tabular}{cc}
\hline Özellik & LDPE \\
\hline Yoğunluk $\left(\mathrm{gr} / \mathrm{cm}^{3}\right)$ & $0.910-0.925$ \\
Sertlik (D) & $41-46$ \\
Erime noktası $\left({ }^{\circ} \mathrm{C}\right)$ & $105-115^{\circ} \mathrm{C}$ \\
Çekme dayanımı $(\mathrm{MPa})$ & $7-40$ \\
Elastik modül $(\mathrm{GPa})$ & $0.07-0.3$ \\
Uzama $(\%)$ & $90-800$ \\
\hline
\end{tabular}


Tablo 3. TEOA’nın özellikleri (Geçkil vd., 2020)

\begin{tabular}{cc}
\hline Özellik & TEOA \\
\hline Kimyasal formül & $\mathrm{C}_{6} \mathrm{H}_{15} \mathrm{NO}_{3}$ \\
Molar kütle & $149.19 \mathrm{gr} / \mathrm{mol}$ \\
Kaynama noktasi $\left({ }^{\circ} \mathrm{C}\right)$ & $335.4\left({ }^{\circ} \mathrm{C}\right)$ \\
Yoğunluk $\left(\mathrm{gr} / \mathrm{cm}^{3}\right)$ & $1.12 \mathrm{gr} / \mathrm{cm}^{3}$ \\
Yap1 & Bazik \\
\hline
\end{tabular}

\subsection{Metot}

Çalışmada, LDPE katkılı bağlayıcılar elde etmek amaciyla, ilk olarak $160^{\circ} \mathrm{C}$ sicaklığa kadar isitılan saf asfalta ağırlıç̧a \%2.5'i kadar TEOA ilave edilerek karıştırma işlemi 500 devirde 10 dakika boyunca Şekil 2'deki karıştırma cihazıyla yapılmıştır. TEOA oranı, karıştırma süresi ve devir sayısı laboratuvarda gerçekleştirilen ön çalışmalar sonucunda tespit edilmiştir. Daha sonra, asfalt ağırlığının \%1, 2, 3, 4 ve 5 oranlarında LDPE ilave edilerek, 1000 devirde 50 dakika boyunca aynı sıcaklıkta karıştırma işlemi devam ettirilmiştir. Tüm modifiye asfaltların hazırlanmasında aynı prosedür takip edilmiştir.

Saf ve LDPE katkılı asfaltlar çalışmada sırasıyla B, $\mathrm{B}+\% 1 \mathrm{~L}, \mathrm{~B}+\% 2 \mathrm{~L}, \mathrm{~B}+\% 3 \mathrm{~L}, \mathrm{~B}+\% 4 \mathrm{~L}$ ve $\mathrm{B}+\% 5 \mathrm{~L}$ olarak kodlanmıştır.

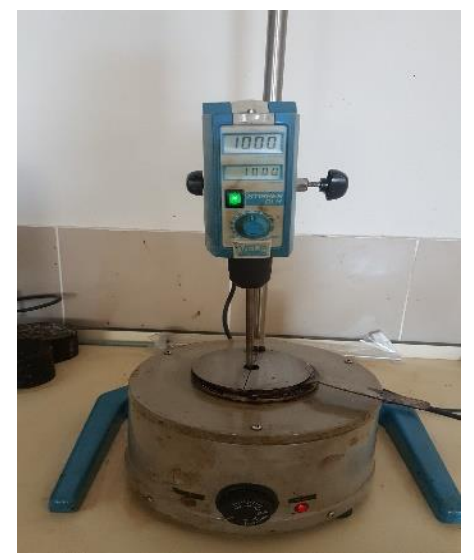

Şekil 2. Karıştırma cihazı

\section{Deneysel yöntem}

Saf ve LDPE katkılı asfalt bağlayıcıların ilk olarak fiziksel özellikleri penetrasyon, yumuşama noktas1, düktilite ve dönel ince film etüvü (RTFO) gibi geleneksel testlerle tespit edilmiştir. Ayrıca bağlayıcıların sıcaklığa karşı hassasiyetlerinin bir ölçüsü olarak bilinen Penetrasyon Indeksi (PI) değerleri de hesaplanmıştır. Daha sonra bağlayıcıların işlenebilirlik özellikleri dönel viskozimetre (RV) deneyi ile, kimyasal karakterizasyonu ise taramalı elektron mikroskobu
(SEM) ve X- 1şını kırınımı (XRD) analizleri ile belirlenmiştir.

\subsection{Saf ve LDPE katkul asfaltlarin fiziksel özelliklerinin belirlenmesi}

\subsubsection{Penetrasyon deneyi}

ASTM D5 standardına göre asfalt bağlayıcıların sertliğini veya kıvamını belirlemek amaciyla penetrasyon deneyi gerçekleştirilmektedir. Deney, 100 gr ağırlığındaki bir iğnenin $25^{\circ} \mathrm{C}$ sıcaklıkta 5 saniye süreyle asfalt içerisinde ilerlediği düş̧ey mesafe olarak tanımlanmaktadır. Birimi $10^{-1} \mathrm{~mm}$ olan deneyde kullanılan penetrasyon cihazı Şekil 3a'da verilmiştir.

\subsubsection{Yumuşama noktası deneyi}

ASTM D36 standardına göre gerçekleştirilen yumuşama noktası deneyinde asfalt bağlayıcıların yüksek sıcaklıklara karşı direncini ölçmeyi amaçlar. Deney, üzerine standart bir bilye yerleştirilmiş olan asfalt bağlayıcının belirli bir hızda 1sıtılması sonucunda gevşemiş bağlayıcının tabana temas ettiği andaki sıcaklık ölçülerek gerçekleştirilir. Yumuşama noktası cihazı Şekil $3 b$ 'de verilmiştir.
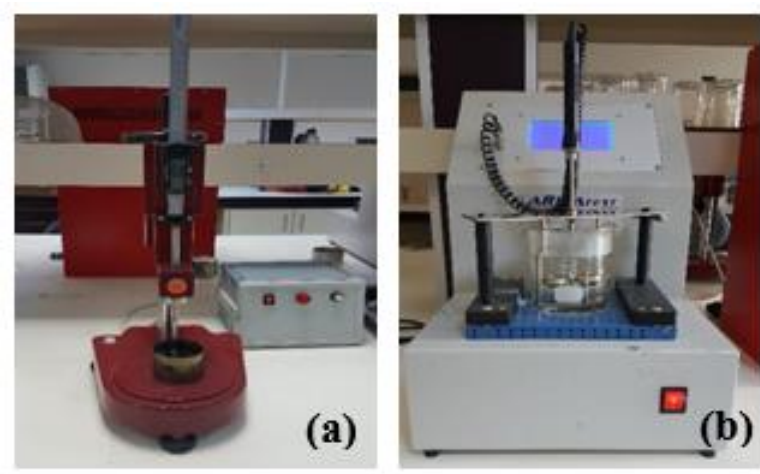

Şekil 3. Penetrasyon (a) ve yumuşama noktası (b) cihaz1 


\subsubsection{Düktilite deneyi}

ASTM D113 standardına göre gerçekleştirilen düktilite deneyinde asfalt bağlayıcıların uzama kabiliyeti ve kohezyon mukavemetini belirlenir. Deney, standart kalıp içerisinde hazırlanmış asfaltın, $25^{\circ} \mathrm{C}$ sicaklıkta ve $5 \mathrm{~cm} /$ dakika hizla her iki ucundan çekilerek kopuncaya kadar uzadığı mesafenin $\mathrm{cm}$ cinsinden ifadesidir. Düktilite cihazı Şekil 4a'da verilmiştir.

\subsubsection{RTFO deneyi}

Asfalt bağlayıcıların zaman içerisinde sıcaklık, basınç ve diğer çevre etkileri ile bünyelerinde meydana gelen kayıp "yaşlanma" olarak ifade edilmektedir. Bağlayıcıların servis öncesi süreçte (karıştırma-sıkıştırma, taşıma ve depolama gibi) sıcaklık ve hava etkileriyle yaşlanması "kısa süreli yaşlanma" olarak isimlendirilmektedir. Laboratuvar ortamında asfalt bağlayıcıların kısa süreli yaşlanması dönel ince film etüvü deneyi (RTFOT) ile simüle edilmektedir. RTFOT, ASTM D2872 standardına göre gerçekleştirilir ve deneyde asfalt bağlayıcıdan 35gr'lık numuneler alınarak bu numuneler özel şişeler içerisine doldurulur (Şekil 4b). Daha sonra, bu şişeler $163{ }^{\circ} \mathrm{C}$ sicaklıkta dakikada 15 devir yapacak şekilde ayarlanmış olan RTFOT cihazına (Şekil 4c) yerleştirilir ve 80 dakika boyunca şişelere $4000 \pm 200 \mathrm{~mL} /$ dak olacak şekilde hava verilerek numuneler yaşlandırılır. Deney bitiminde asfalt bağlayıcıların bünyelerinde meydana gelmiş olan kütle kaybı, ilk kütle ile son kütle arasındaki farkın ilk kütleye bölünmesi ile belirlenmektedir (Geçkil ve Seloğlu, 2018).
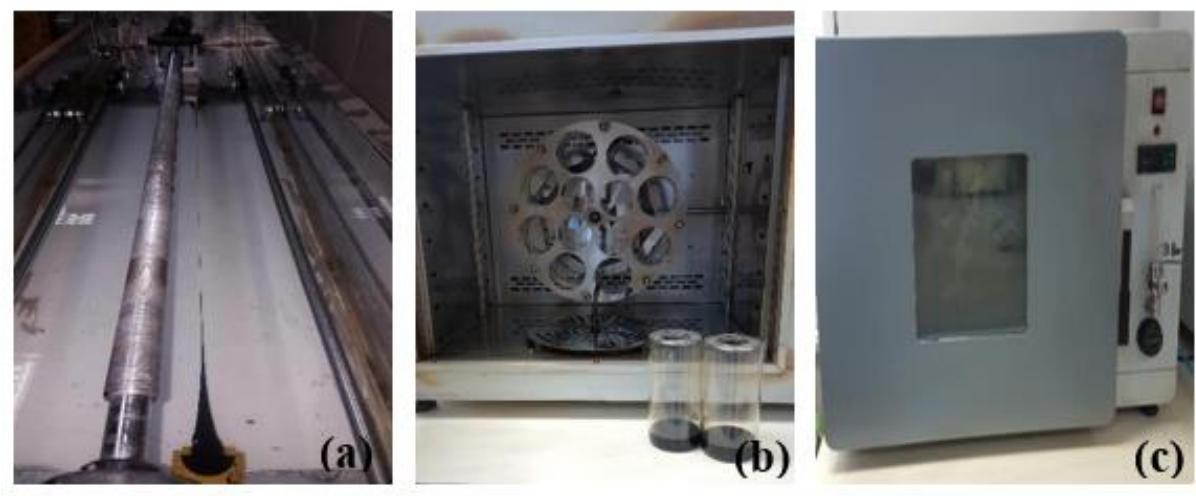

Şekil 4. Düktilite cihazı (a), RTFOT şişeleri (b) ve RTFOT cihazı (c)

Fiziksel özellikleri tespit edilen asfalt bağlayıcıların, sıcaklığa karşı hassasiyetlerinin bir ölçüsü olarak kabul edilen penetrasyon indeksi (PI) değerleri de denklem 1 yardımıyla hesaplanmıştır.

$$
P I=\frac{1952-500 \times \log \left(\text { Pen }_{25}\right)-20 \times \mathrm{SP}}{50 \times \log \left(\text { Pen }_{25}\right)-\mathrm{SP}-120}
$$

Denklem 1'de yer alan $P e_{25}$, bağlayıcıların 25 ${ }^{\circ} \mathrm{C}$ 'deki penetrasyon değerini, $S P$ ise yumuşama noktası değerini ifade etmektedir. PI değerinin artması, asfalt bağlayıcının sıcaklık hassasiyetinin azaldığını ve sertliğinin arttığını göstermektedir. Sıcak karışım hazırlanırken yüksek PI değerine sahip bir asfalt kullanıldığında, karışımların kalıcı deformasyonlara karşı daha dirençli hale geldiği değerlendirilmektedir (Geçkil ve Seloğlu, 2018).

\subsection{Saf ve LDPE katkul asfaltların işlenebilirlik özelliklerinin belirlenmesi}

Asfalt bağlayıcıların yüksek sıcaklıklardaki işlenebilirlik özelliklerinin tayin edilmesinde RV deneyi uygulanmaktadır. Deney, ASTM D 4402 standardına göre gerçekleştirilmektedir. Bağlayıcıların 135 ve $165{ }^{\circ} \mathrm{C}$ sıcaklıklardaki viskozite değerleri kullanılarak pompalanma, karıştırma ve sıkıştırma sırasında bağlayıcıların yeterince akışkan olduklarının tespit etmek amacıyla belirlenmektedir. Bağlayıcıların karıştırma ve sıkıştırma sıcaklıklarının tespiti için Amerikan Asfalt Enstitüsü tarafindan, bağlayıcıların $135{ }^{\circ} \mathrm{C}$ ve $165{ }^{\circ} \mathrm{C}$ 'deki viskozite değerlerinin tespit edilmesi önerilmektedir. Bununla birlikte, bağlayıcıların $135^{\circ} \mathrm{C}^{\prime}$ deki viskozite değerlerinin 3000 cP'yi aşmaması beklenmektedir. Deney bitiminde elde edilen viskozite değerleri yardımıyla bağlayıcıların viskozite-sıcaklık grafiğgi çizilmekte ve buradan HMA'ın karıştırma ve sıkıştırma sıcaklık aralıkları da belirlenebilmektedir. Karıştırma ve sıkıştırma sicaklıklarının tespit edilmesi için sırasıyla $170 \pm 20$ ve $280 \pm 30 \mathrm{cP}$ viskozite sınırlarına karşılık gelen sıcaklık aralıklarının kullanılması önerilmektedir (Geçkil, 2008). Deneyde kullanılan RV cihazı Şekil 5'te, asfalt bağlayıcıların tipik viskozitesıcaklık eğrisi ise Şekil 6'da verilmiştir. 


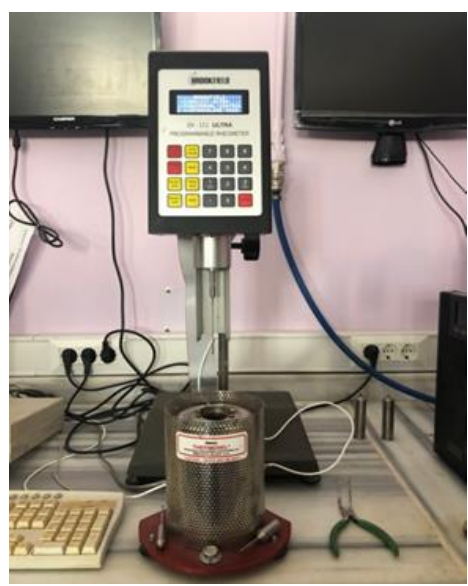

Şekil 5. RV cihazı

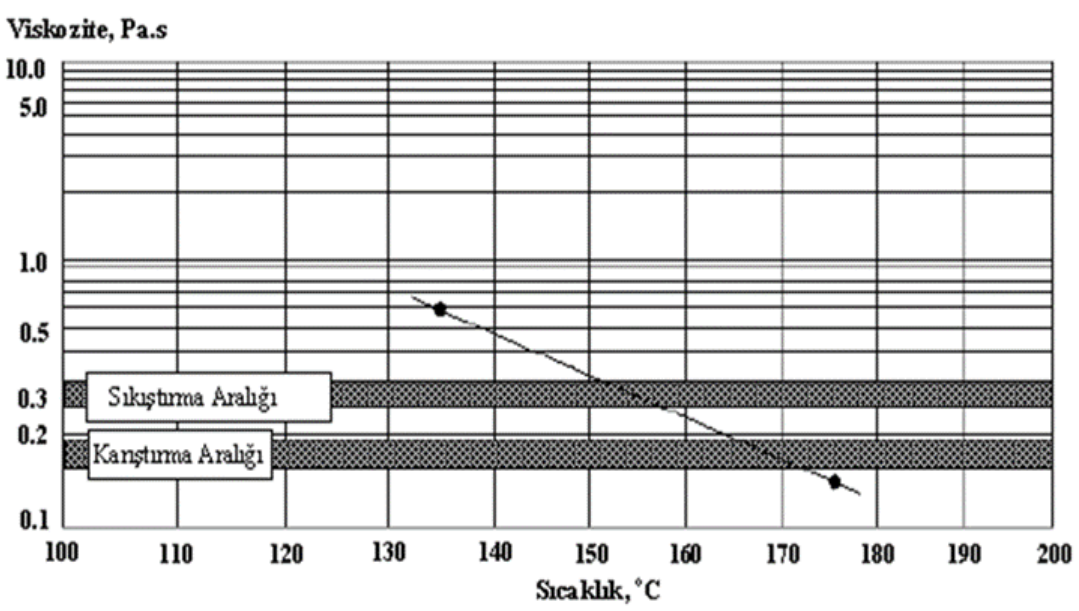

Şekil 6. Asfalt Bağlayıcı İçin Tipik Viskozite Eğrisi (Geçkil, 2008)

3.3. Saf ve LDPE katkilı asfaltlarin kimyasal karakterizasyonu

Asfalt bağlayıcıların kimyasal karakterizasyonunda birçok analiz kullanılsa da SEM ve XRD bunlardan en sik kullanılanlarıdır. Asfalt+katk1 malzemesinin uyumu ve faz yapıları SEM görüntüleri yardımıyla belirlenmektedir
(Mazumder vd., 2018). Asfalt bağlayıcının yapısındaki kristal, amorf vb. bölgeleri tanımlamak ve asfaltın yapısal özelliklerini analiz etmek için XRD analizi kullanılmaktadır (Alhumaidan vd., 2015). Çalışmada saf ve LDPE katkılı asfalt bağlayıcıların SEM görüntülerini ve XRD desenlerini elde etmede kullanılan cihazlar Şekil 7'de verilmiştir.
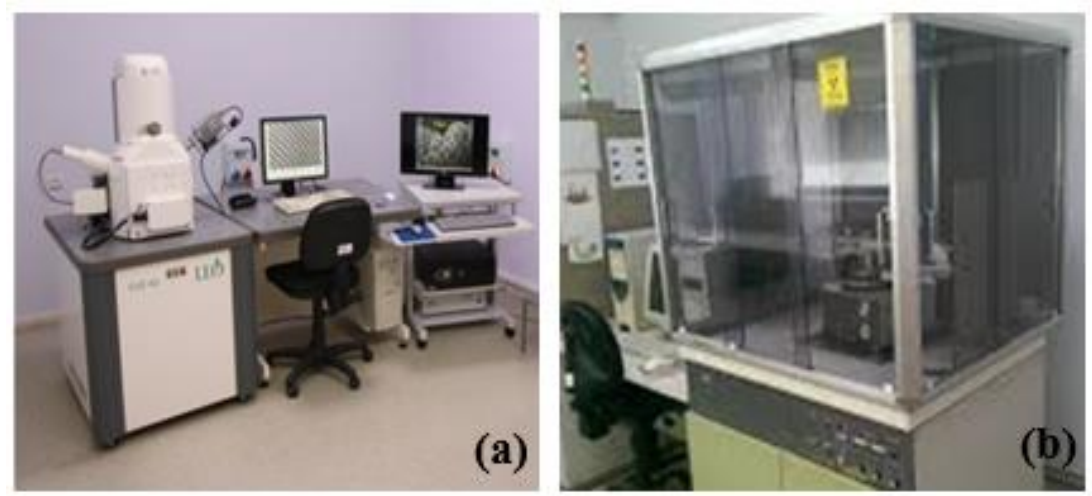

Şekil 7. SEM (a) ve XRD (b) cihazı 


\section{Deneysel bulgular}

\subsection{Fiziksel test sonuçları}

Saf ve LDPE katkılı asfalt bağlayıcıların fiziksel özellikleri penetrasyon, yumuşama noktası, düktilite ve RTFO deneyi ile belirlenmiştir. Ayrıca tüm bağlayıcıların PI değerleri de hesaplanarak elde edilen tüm sonuçlar Tablo 4'de, bağlayıcıların fiziksel özelliklerinin LDPE içeriklerine göre değişimi ise sırasıyla Şekil 8-10'da verilmiştir.

Tablo 4. Fiziksel test sonuçları

\begin{tabular}{|c|c|c|c|c|c|c|}
\hline \multirow[t]{2}{*}{ Özellik } & \multicolumn{6}{|c|}{ Bağlayıcı türü } \\
\hline & B & $\mathrm{B}+\% 1 \mathrm{~L}$ & $\mathrm{~B}+\% 2 \mathrm{~L}$ & $\mathrm{~B}+\% 3 \mathrm{~L}$ & B +\% $\%$ L & B +\%5L \\
\hline Penetrasyon $(0.1 \mathrm{~mm})$ & 88 & 75.9 & 65.6 & 64.5 & 58.1 & 56.9 \\
\hline Yumuşama noktası $\left({ }^{\circ} \mathrm{C}\right)$ & 46.8 & 49.3 & 51.5 & 52.8 & 57.4 & 59.2 \\
\hline Düktilite $(\mathrm{cm})$ & 117 & 112 & 108 & 106 & 101 & 99 \\
\hline PI & -0.63 & -0.34 & -0.17 & 0.11 & 0.88 & 1.20 \\
\hline \multicolumn{7}{|l|}{$\underline{\text { RTFOT sonrast }}$} \\
\hline Kütle kaybı (\%) & 0.23 & 0.54 & 0.56 & 0.57 & 0.58 & 0.53 \\
\hline
\end{tabular}

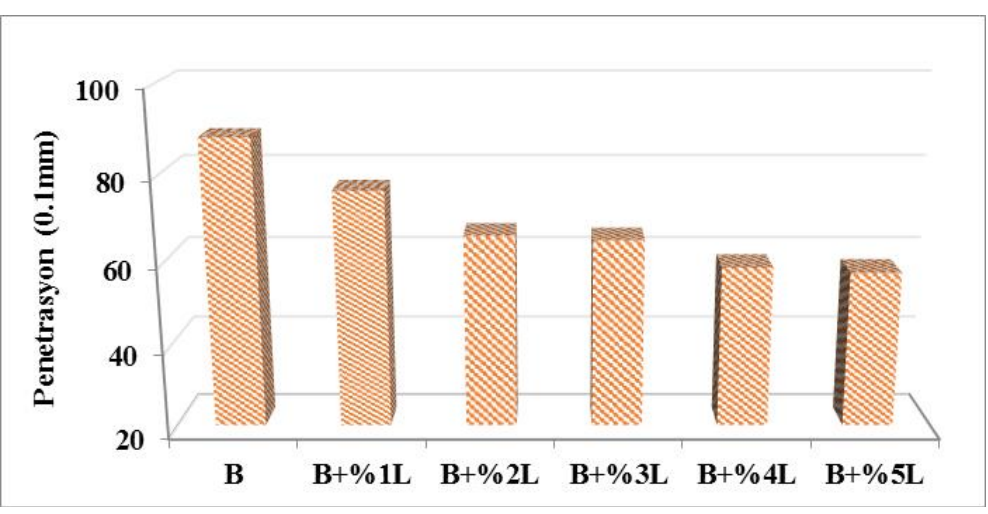

Şekil 8. Bağlayıcıların penetrasyon değişimleri

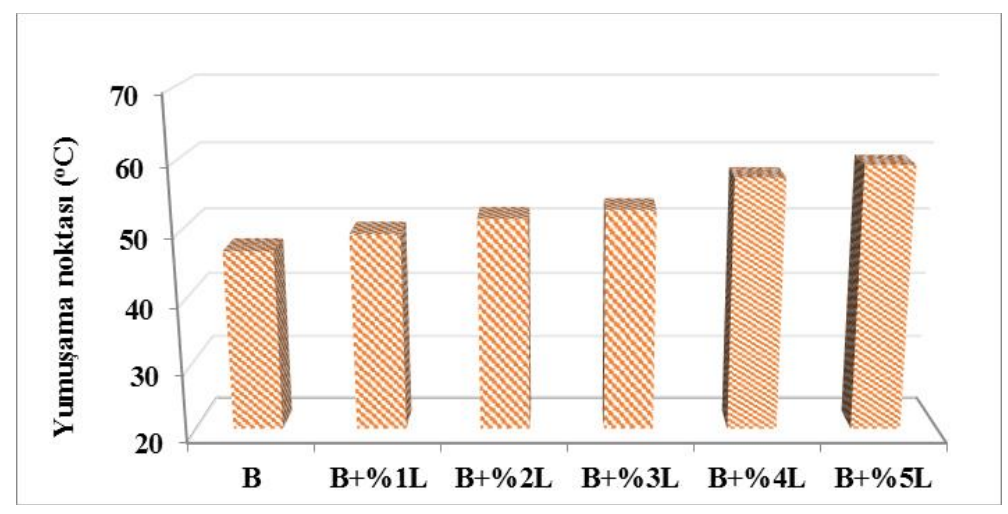

Şekil 9. Bağlayıcıların yumuşama noktası değişimleri

Şekil 8'de görüldüğü gibi, saf asfalta (B) LDPE katkısıyla modifiye bağlayıcıların penetrasyon değerlerinde saf asfalta kıyasla değişimler meydana gelmiştir. Bu değişimler sırasıyla \%13.8; $\% 25.5 ; \% 26.7 ; \quad \% 33.9$ ve $\% 35.3$ azalma şeklindedir. LDPE ilavesiyle oluşan bu sertleşmenin doğal bir sonucunda modifiye bağlayıcıların yumuşama noktası değerlerinde de değişimler meydana gelmiştir (Şekil 9). Bu değişimler saf asfalta kıyasla sırasıyla $\% 5.3 ; \% 10$; $\% 12.8 ; \% 22.6$ ve $\% 26.5$ artış şeklindedir.
Şekil 10 incelendiğinde, LDPE artışıla bağlayıcıların düktilite değerlerinde değişimler meydana geldiği görülmektedir. Bu değişimler saf asfalta kiyasla sirasiyla $\% 4.3 ; \% 7.7 ; \% 9.4 ; \% 13.7$ ve $\% 15.4$ azalma şeklindedir.

Elde edilen bu sonuçlar birlikte değerlendirildiğinde, penetrasyon ve yumuşama noktası sonuçlarına göre, modifiye bağlayıcıların kıvamında önemli sertleşme meydana geldiği ve asfalt sınıfinın B 50/70 olarak değiştiği 
görülmektedir. $\mathrm{Bu}$ durumda, modifiye bağlayıcıların yüksek sıcaklığın hüküm sürdüğü bölgelerde kalıcı deformasyonlara karşı kullanılabileceği ifade edilebilir. Düktilite değerlerinde meydana gelen azalmalar modifiye bağlayıcıların uzama yeteneğinde kısmi bir azalma olduğunu ve buna bağlı olarak kohezyon yeteneğinin düştüğünü göstermektedir. Ayrıca artış ve azalış oranlarının \%4 LDPE oranında pik yaptığı, bu orandan sonra değişimlerin azaldığ görülmektedir.

B 70/100 saf asfaltına LDPE ilavesiyle elde edilen modifiye bağlayıcıların PI değerlerinde meydana gelen değişimler Şekil 11'de verilmiştir.
Şekil 11'de, saf asfalta LDPE ilavesiyle modifiye bağlayıcıların PI değerlerinin artış gösterdiği görülmektedir. PI değerlerindeki artış, asfalt bağlayıcıların kalıcı deformasyonlara karşı daha dirençli olduğunu göstermektedir. Bu durumda, LDPE katkısıyla modifiye bağlayıcıların sıcaklığa karşı hassasiyetlerinin azaldığını söylemek mümkündür.

Saf ve LDPE katkılı bağlayıcıların bünyelerinde meydana gelen kütle kaybı değișimleri Şekil 12'de verilmiştir.

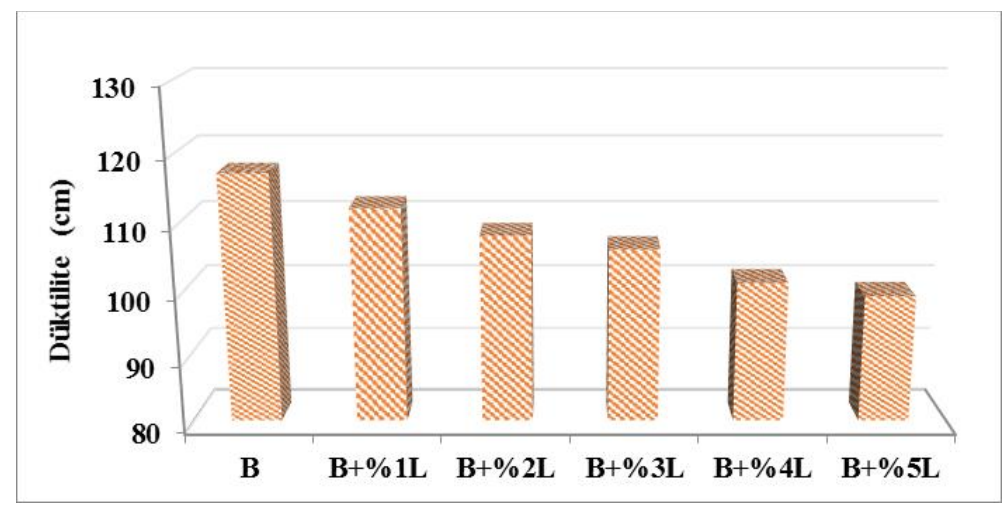

Şekil 10. Bağlayıcıların düktilite değişimleri

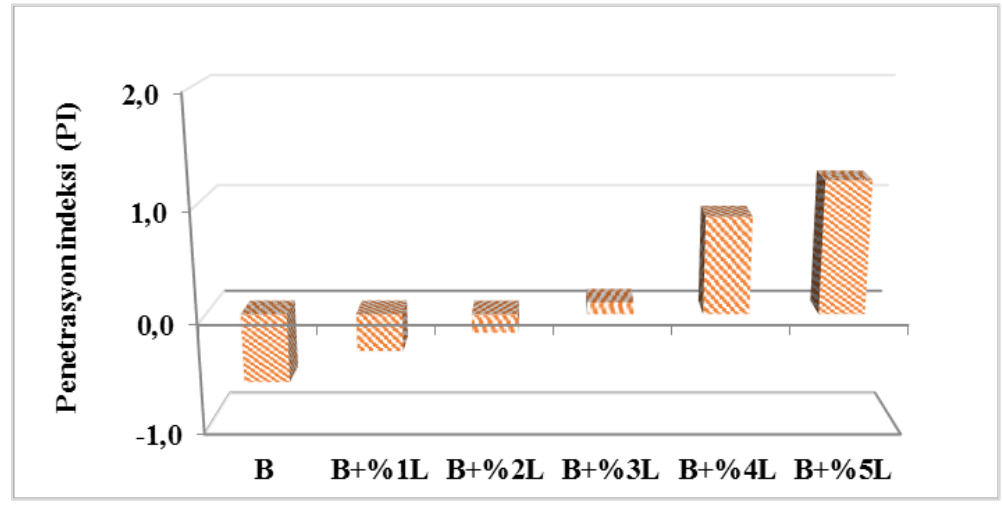

Şekil 11. Bağlayıcıların PI değiş̧imleri

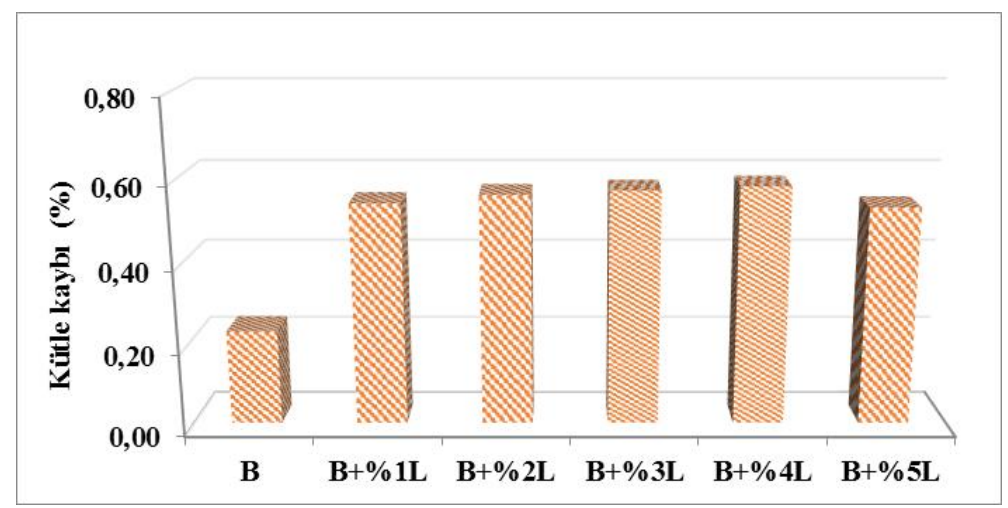

Şekil 12. Bağlayıcıların kütle kaybı değişimleri 
Şekil 12 incelendiğinde, LDPE katkısıyla bağlayıcıların bünyelerinde oluşan kütle kayıplarının şartnamenin öngördüğ̈̈ sınırın (maks. 0.8 ) oldukça altında olduğu görülmektedir. $\mathrm{Bu}$ durum, LDPE katkısının modifiye bağlayıcıların yaşlanması veya sertleşmesi üzerinde olumsuz bir etkiye sahip olmadığını göstermektedir. Ayrıca LDPE modifiyeli bağlayıcıların sıcaklık ve oksidasyona karşı dirençli olduğunu da söylemek mümkündür.

\section{2. $R V$ test sonuçları}

Saf ve LDPE katkılı bağlayıcıların, $135^{\circ} \mathrm{C}$ ve 165 ${ }^{\circ} \mathrm{C}$ sicaklıklardaki viskozite değerleri Brookfield DV-III cihazı kullanılarak belirlendi. Asfalt bağlayıcıların işlenebilirlik sıcaklıkları olan plentteki karıştırma ve yoldaki serme sıcaklıkları, belirlenen bu viskozite değerleri yardımıyla oluşturulan sicaklık-viskozite grafiği yardımı ile tespit edildi. Saf ve LDPE katkılı bağlayıcıların sicaklık-viskozite grafiği Şekil 13'te, ortalama karıştırma ve sıkıştırma sıcaklıkları ise Şekil 14'de verilmiştir.
Şekil 13'te görüldüğü gibi, LDPE katk1 ilavesiyle modifiye bağlayıcıların viskozite değerleri $\left(135^{\circ} \mathrm{C}\right.$ ve $165^{\circ} \mathrm{C}$ ) önemli oranda artış göstermiştir. $\mathrm{Bu}$ artışlar, $135{ }^{\circ} \mathrm{C}$ 'de saf asfalta kıyasla sırasıyla $\% 50.4 ; \% 94.9 ; \% 145.3 ; \% 367.5$ ve $\% 443.6 ; 165$ ${ }^{\circ} \mathrm{C}^{\prime}$ de ise $\% 27.8 ; \% 69.5 ; \% 111.3 ; \% 336.1$ ve $\% 433.3$ gibi yüksek oranlarda meydana gelmiştir.

Bağlayıcıların ortalama karıştırma ve sıkıştırma sicaklıklarındaki değişim ise (Şekil 14) saf asfalta kıyasla sırasıyla karıştırma için \%2.0; \%3.5; \%4.0; $\% 7.2$ ve $\% 8.3$; sıkıştırma için $\% 4.1 ; \% 7.3 ; \% 8.8$; $\% 13.3$ ve \%14.4 artı̧s şeklindedir. Meydana gelen bu artışlar dikkate alındığında, artış hızının \%4 oranından sonra azalmaya başladığı görülmektedir. $\mathrm{Bu}$ sonuçlarına göre, LDPE katkısı ile bağlayıcıların kıvamında sertleşme meydana geldiği ve yüksek sıcaklıklardaki akışkanlık özelliklerinin büyük oranda azaldığı, bunun sonucunda ise ortalama karıştırma-sıkıştırma sıcaklıklarının saf asfalta kıyasla artış gösterdiği görülmektedir.

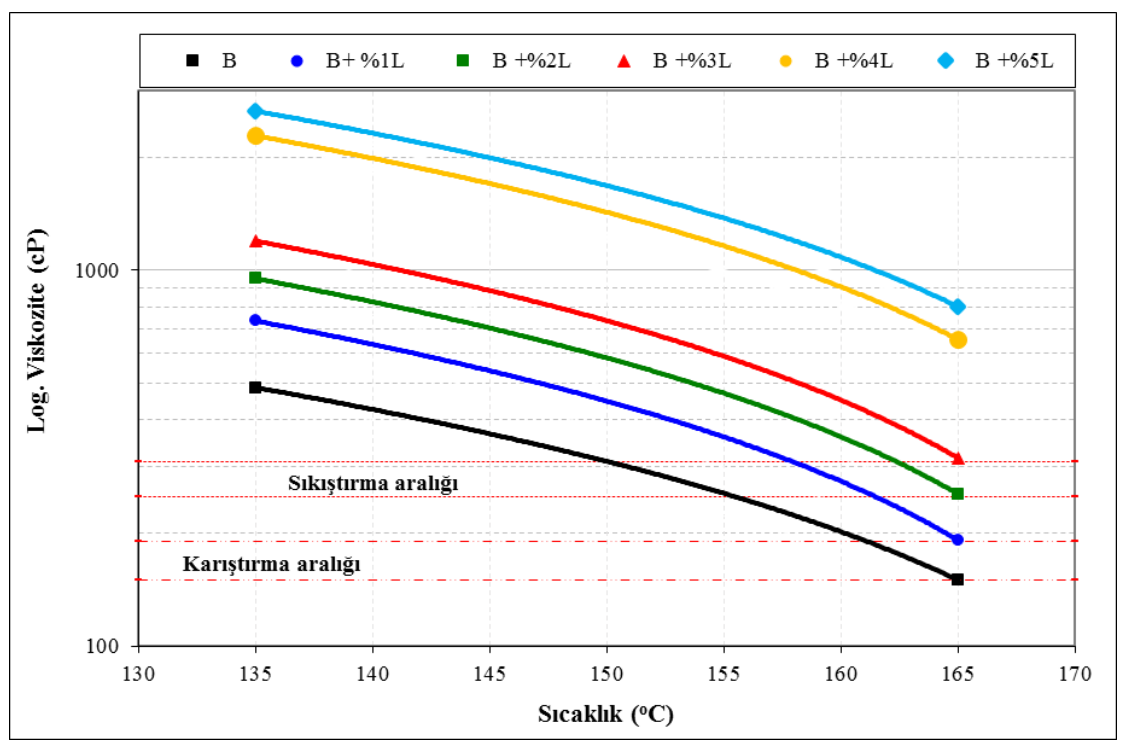

Şekil 13. Bağlayıcıların sıcaklık-viskozite ilişkisi

$\mathrm{Bu}$ durum, LDPE katkılı bağlayıcıların plentte karıştırma ve yolda serme esnasında enerji sarfiyatını arttırabileceğini ifade etmektedir. Ancak, atık LDPE katkısının çevreye ve canlılara vermiş olduğu zararlar ve HMA kaplamada göstereceği yararlar göz önüne alındığında bu enerji sarfiyatının göz ardı edilebileceği değerlendirilmektedir. 


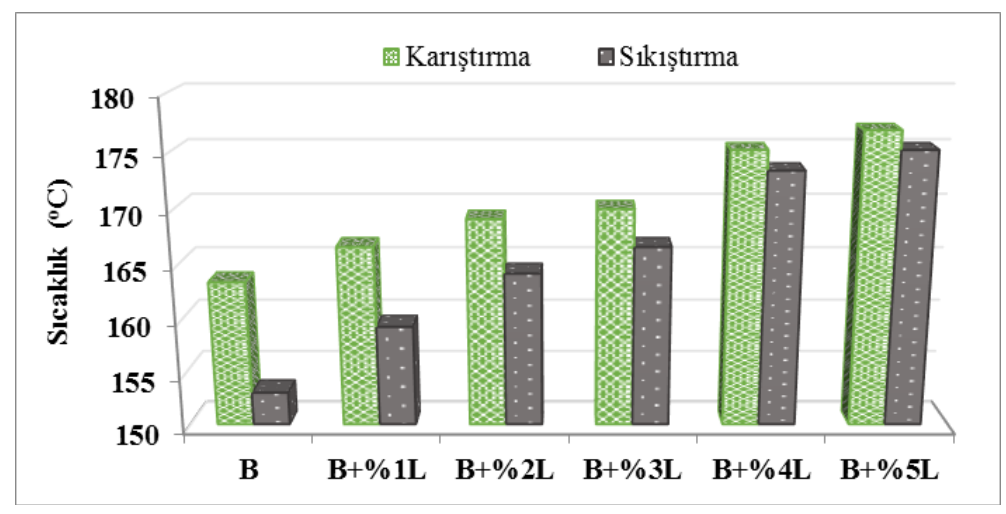

Şekil 14. Bağlayıcıların ortalama karıştırma-sıkıştırma sıcaklıkları

\subsection{Karakterizasyon sonuçları}

Çalışmada saf ve LDPE katkılı bağlayıcıların kimyasal yapısında meydana gelen değişimler SEM ve XRD analizleri ile belirlenmiştir. $\mathrm{Bu}$ amaçla saf asfalt (B) ile kritik oran olan $\mathrm{B}+\% 4 \mathrm{~L}$ bağlayıcılarının SEM görüntüleri ve XRD desenleri Şekil 15'de verilmiştir.

Şekil 15a'da saf asfaltın (B) SEM görüntüsü incelendiğinde, yapının oldukça homojen ve tek fazlı olduğu görülmektedir. Saf asfalta \%4 LDPE+TEOA ilave edildiğinde ise (Şekil 15b), saf asfaltta olduğu gibi homojen ve tek fazlı bir yapının korunduğu görülmektedir. Saf asfaltın (B) XRD deseni incelendiğinde ise, iki farklı makromoleküler yapının mevcut olduğu görülmektedir. $2 \theta \cong 20^{\circ}$ civarında elde edilen ilk pik geniş ve yayvan olan kristalin bölgeyi, $2 \theta \cong 40^{\circ}$ civarında elde edilen ikinci pik ise daha az alana sahip olan amorf bölgenin varlığını göstermektedir. $\mathrm{B}+\% 4 \mathrm{~L}$ bağlayıcısının XRD deseninde ise saf asfalta göre pik şiddetinin $\left(2 \theta \cong 20^{\circ}\right)$ arttı̆g 1 ve kristalin bölgelerin kısmen arttı̆̆ 1 , ancak LDPE katkısıyla $2 \theta \cong 40^{\circ}$ civarındaki pikin giderek yayvanlaşmaya başladığı ve amorf yapının giderek arttığ 1 görülmüştür. Bu durum, LDPE katkısının asfalt+TEOA harmanıyla birleştiğinde yapıyı amorflaştırdığı ve kimyasal bir reaksiyona girdiği olarak yorumlanmaktadır.
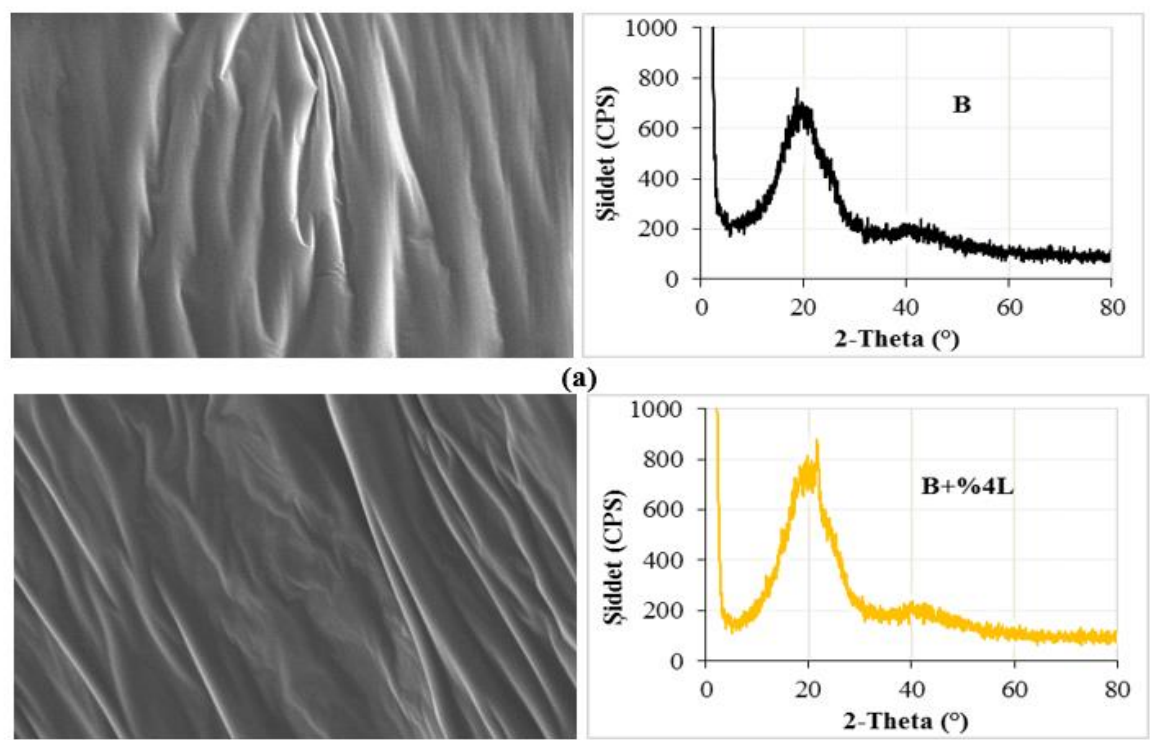

(b)

Şekil 15. Bağlayıcıların SEM görüntüleri ve XRD desenleri; (a) B; (b) B+\%4L

\section{Sonuçlar}

Bu çalışmada, bir atık plastik çeşidi olan LDPE'nin asfaltın fiziksel ve işlenebilirlik özelliklerine etkisi araştırılmış ve aşağıdaki sonuçlar elde edilmiştir.
1. Penetrasyon sonuçlarına göre, LDPE katkı oranının artışı ile modifiye bağlayıcıların sertliğinin arttığ1 ve penetrasyon sinıfi B 50/70 asfalta dönüştüğü görülmüştür. 
2. Yumuşama noktası sonuçlarına göre, elde edilen sonuçların penetrasyon sonuçları ile uyumlu olduğu ve LDPE katkısıyla bağlayıcıların sertleşmesi sonucunda yumuşama noktası değerlerinin de yükseldiği görülmüştür. $\mathrm{Bu}$ sonuçlara göre, LDPE katkısıyla modifiye bağlayıcıların yüksek sıcaklıklardaki deformasyon direncinin arttığı ve daha sicak bölgelerde kullanılabileceği görülmüsstür.

3. Düktilite sonuçlarına göre, LDPE katkısıyla modifiye bağlayıcıların uzama kabiliyetinin ve kohezyon mukavemetinin azaldığı görülmüştür.

4. PI sonuçları değerlendirildiğinde, LDPE ilavesiyle bağlayıcıların sıcaklık hassasiyetinin azaldığı görülmüştür.

5. Kütle kaybı sonuçlarına göre, LDPE katkısının modifiye bağlayıcıların yüksek sicaklık ve oksidasyon direnci üzerinde olumlu bir etkiye sahip olduğu görülmüştür.

6. RV sonuçlarına göre, LDPE katkısıyla bağlayıcıların akıcılıklarının azaldığ sonucunda bağlayıcıların karıştırma-sıkıştırma sıcaklıklarının artış göstererek daha fazla enerji tüketimi gerektireceği görülmüştür. Ancak, atık LDPE'nin çevreye ve canlılara vermiş olduğu zararlar göz önüne alındığında bu enerji sarfiyatının göz ardı edilebileceği ifade edilebilir.

Sonuç olarak, atık LDPE'nin asfaltın kıvamını sertleştirdiği ve karıştırma-sıkıştırma sıcaklıklarını arttırdığ 1 tespit edilmiştir. Ancak, LDPE'nin karayolu mühendisliğinde bir katk1 olarak kullanılmasının, bu atıkların çevreye ve canlılara vermiş olduğu zararları azaltacağı ve ülke ekonomisine bir katma değer sağlayabileceği değerlendirilmektedir.

\section{Teşekkür}

Bu çalışma, İnönü Üniversitesi Bilimsel Araştırma Projeleri (BAP) Koordinasyon Biriminin İÜ-BAP FYL 2016/99 numaralı projesi ile desteklenmiştir. Desteklerinden dolayı BAP Koordinasyon Birimine teşekkür ederiz.

\section{Kaynaklar}

Ahmedzade, P., Fainleib, A., Günay, T. and Grygoryeva, O. (2014). Modification of bitumen by electron beam irradiated recycled low density polyethylene. Construction and Building Materials, $69, \quad 1-9$. https://doi.org/10.1016/j.conbuildmat.2014.07.0 27
Airey, G.D. (2002). Rheological evaluation of ethylene vinyl acetate polymer modified bitumens. Construction and Building Materials, 16(8), 473$487 . \quad$ https://doi.org/10.1016/S09500618(02)00103-4

Al-Hadidy, A.I. and Tan, Y. (2009). Evaluation of pyrolisis LDPE modified asphalt paving materials. Journal of Materials in Civil Engineering, 21(10), 618-623. https://doi.org/10.1061/(ASCE)08991561(2009)21:10(618)

AlHumaidan F.S., Hauser, A., Rana, M.S., Lababidi, H.M.S. and Behbehanii M. (2015). Changes in asphaltene structure during thermal cracking of residual oils: XRD study. Fuel, 150, 558-564. https://doi.org/10.1016/j.fuel.2015.02.076

Almeida, A., Capitao, S., Bandeira, R., Fonseca, M. and Picado-Santos, L. (2020). Performance of AC mixtures containing flakes of LDPE plastic film collected from urban waste considering ageing. Construction and Building Materials, 232, 117253. https://doi.org/10.1016/j.conbuildmat.2019.1172 53

Awwab, M.T. and Shbeeb, L. (2007). The use of polyethylene in hot asphalt mixtures. American Journal of Applied Sciences, 4(6), 390-396.

Behl, A., Sharma, G. and Kumar, G. (2014). A sustainable approach: utilization of waste PVC in asphalting of roads. Construction and Building Materials 54, 113-117. https://doi.org/10.1016/j.conbuildmat.2013.12.0 50

Besergil, B. (2008). Polimer kimyası (ikinci baskı). Ankara: Gazi Kitapevi.

Duranay, N. ve Yılgın, M. (2016). Atık plastiğin kömür ve biokütle ile birlikte yakılarak değerlendirilmesi. Firat Üniversitesi Mühendislik Bilimleri Dergisi, 28 (2), 35-42.

Geçkil, T. (2008). Siyah karbonun bitümlü sıcak karışımların özelliklerine etkisinin araştırılması. Doktora Tezi, Frrat Üniversitesi Fen Bilimleri Enstitüsü, Elazı ̆.

Geçkil, T. and Seloğlu, M. (2018). Performance properties of asphalt modified with reactive terpolymer. Construction and Building Materials, 173, 262-271. https://doi.org/10.1016/j.conbuildmat.2018.04.0 36

Geçkil, T., Önal, Y. ve İnce, C.B. (2020). Atık polietilen tereftalat (PET) ile Modifiye edilmiş saf bitümün fiziksel, morfolojik ve isıl özellikleri. Firat Üniversitesi Mühendislik Bilimleri Dergisi, 
32(1),

$157-166$.

https://doi.org/10.35234/fumbd.618218

Jasso, M., Hampl, R., Vacin, O., Bakos, D. and Zanzotto, L. (2015). Rheology of conventional asphalt modified with sbs, elvaloy and polyphosphoric acid. Fuel Proccessing Technology, 140, 172-179. https://doi.org/10.1016/j.fuproc.2015.09.002

Jung, M.R., Horgen, F.D. and Orski, S.V. (2018). Validation of ATR FT-IR to identify polymers of plastic marine debris, including those ingested by marine organisms. Marine Pollution Bulletin, 127 , 704-716. https://doi.org/10.1016/j.marpolbul.2017.12.061

Mazumder, M., Ahmed, R., Ali, A.W. and Lee, S.J. (2018). SEM and ESEM techniques used for analysis of asphalt binder and mixture: A state of the art review. Construction and Building Materials, 186, 313-329. https://doi.org/10.1016/j.conbuildmat.2018.07.1 26

Nejres, M., Mustafa, Y.F. and Aldewachi, H.S. (2020). Evaluation of natural asphalt properties treated with egg shell waste and low density polyethylene. International Journal of Pavement Engineering,

$1029-8436$. https://doi.org/10.1080/10298436.2020.1728534
Njeru, J. (2006). The urban political ecology of plastic bag waste problem in Nairobi, Kenya. Geoforum, 37, 1046-1058.

Nkanga, U.J., Joseph, J.A., Adams, F.V. and Uche, O.U. (2017). Characterization of bitumen/plastic blends for flexible pavement application. Procedia Manufacturing, 7, 490-496. https://doi.org/10.1016/j.promfg.2016.12.051

Polacco, G., Filippi, S., Merusi, F. and Stastna, G. (2015). A review of the fundamentals of polymer-modified asphalts: asphalt/polymer interactions and principles of compatibility. Advances in Colloid and Interface Science, 224, 72-112. https://doi.org/10.1016/j.cis.2015.07.010

Punith, V.S. and Veeraragavan. A. (2007). Behavior of asphalt concrete mixtures with reclaimed polyethylene as additive. Journal of Materials in Civil Engineering, 19, 500-507. https://doi.org/10.1061/(ASCE)08991561(2007)19:6(500)

Sen, S.K. and Raut, S. (2015). Microbial degradation of low density polyethylene (LDPE): A review. Journal of Environmental Chemical Engineering, 3, $462-473$ https://doi.org/10.1016/j.jece.2015.01.003

Tunç, A. (2007). Yol Malzemeleri ve Uygulamaları. Ankara: Nobel Yayın Dağıtım. 